\title{
POSSIBLE USE OF A GEOGRAPHICAL INFORMATION SYSTEM WITHIN CRISIS MANAGEMENT SIMULATIONS \\ Michaela Jánošíková ${ }^{1}$, Jozef Ristvej$^{2}$, Maroš Lacinák ${ }^{3}$
}

\begin{abstract}
In this paper we deal with Global Information Systems (GIS) used within simulations of crisis management through the phases of the Crisis Management Cycle. In the first part of this paper we point out the short description of the phases and the possible use of GIS within these phases and in simulations within crisis management. In the second part we introduce the GIS in the Slovak Republic with focuses on use in crisis management. The third part is giving possibilities of the interconnections among simulation technologies and GIS within crisis management with a focus on the newly built Laboratory of Modelling and Simulation of Crisis Phenomena in Transport and in different environments. Within conclusions we would like to point out the possibilities for further discussions and directions within this interesting and important topic.
\end{abstract}

JEL Classification Numbers: H12; DOI: http://dx.doi.org/10.12955/cbup.v6.1159

Keywords: GIS, Crisis Management, Crisis Management Cycle, Simulation.

\section{Introduction}

Crisis management is an interdisciplinary scientific field which deals with management as a purposefully oriented activity of people and its mission is to create a management methodology with an emphasis on achieving the effectiveness of this activity in relation to the target stated, i.e. the protection of mankind, the material values and the environment against the effects of crisis phenomena during the time we are overcoming them. It has a coordination character; it unifies and directs people of various occupations. Last but not least, crisis management is a managing activity of people who fulfil the management functions in a specific environment different from the common administrative and manufacturing environment. It is also the mastery to be able to solve concrete crisis phenomena and to select corresponding approaches in concrete conditions and the environment.

After more than three decades with the use of computer information systems for crisis management, we can conclude, that these systems are more and more exploited by the professional community of crisis managers. An important paper in this area is the Need for Emergency Management Information Systems (Turoff et al., 2004), with an emphasis on decision-making support. The creators point to the work of crisis managers, especially to the work under pressure in specific and extreme conditions, where crisis managers face an environment of dynamic changes. This concept has been acknowledged in several further studies, by many experts as well as scientists.

\section{The use of GIS in Crisis Management}

In 1998, for the conditions of the Slovak Republic, Šimák (2016) described the basic Model of Crisis Management. The Model consists of 4 main phases: Prevention, Preparedness and Crisis Planning, Reaction, Recovery (including reconstruction). In the modified model of the Crisis Management cycle, Ristvej, et. al. (2015) transformed this basic model into a cycle (Figure 1), consisting of six phases: prevention, mitigation, preparedness (including planning), rescue and relief, recovery and rehabilitation and reconstruction. These phases are performed with two periods, the mitigation period and the recovery period.

When viewing the use of Global Information Systems (GIS) in each of the phases of the Crisis Management Model and Cycle in the Slovak Republic, we will proceed from a modified model of the Crisis Management cycle. Ristvej et al. (2015) summarizes the possibilities of using GIS, which outlines the main activities that can be performed using GIS programs, individual operational tasks and potential users of these programs for each phase of the cycle.

\footnotetext{
${ }^{1}$ Department of Crisis Management, Faculty of Security Engineering, University of Žilina, Univerzitná 8215/1, 010 26, Žilina, Slovakia, michaela.janosikova@ fbi.uniza.sk

${ }^{2}$ Department of Crisis Management, Faculty of Security Engineering, University of Žilina, Univerzitná 8215/1, 010 26, Žilina, Slovakia, Jozef.Ristvej@ fbi.uniza.sk

${ }^{3}$ Department of Crisis Management, Faculty of Security Engineering, University of Žilina, Univerzitná 8215/1, 010 26, Žilina, Slovakia, maros.lacinak @ fbi.uniza.sk
} 


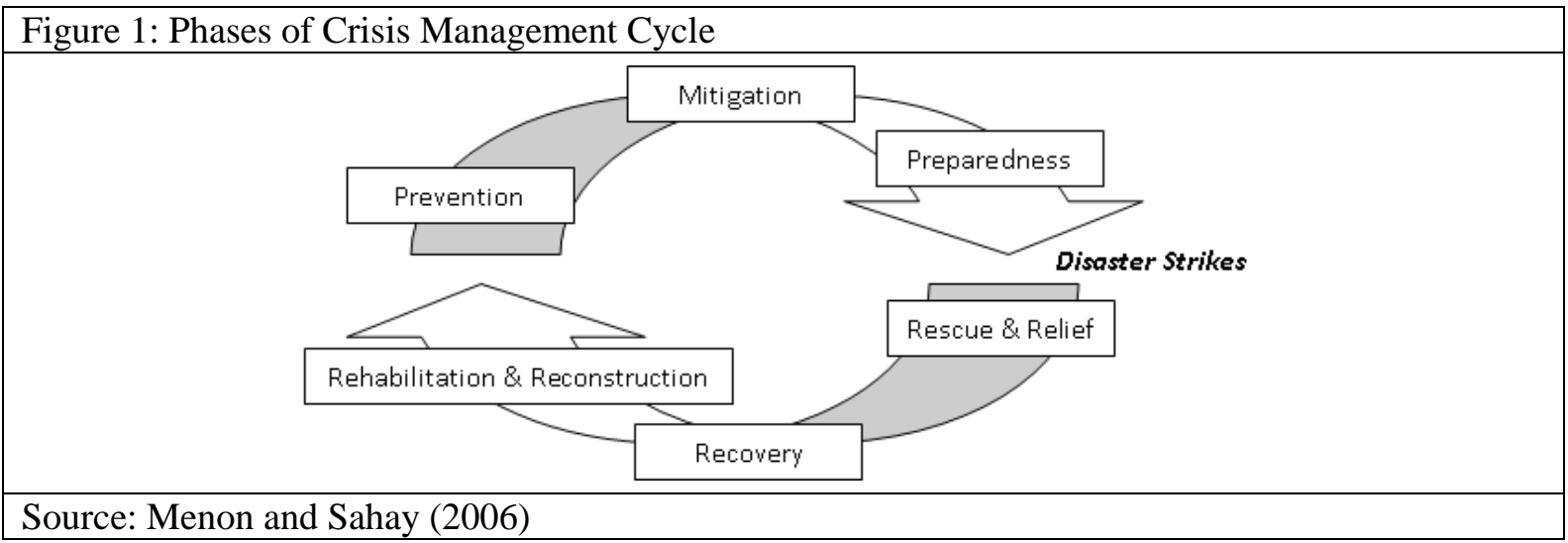

\section{The phase of Prevention (including Mitigation)}

Activities carried out as a part of the prevention of crisis phenomena are focused on minimization, perhaps even for the complete elimination of the probability of such events. Their effectiveness is also driven by the availability of information on the possibilities of emergence of crisis phenomena, their consequences and possible measures.

During this phase it is possible to use GIS in particular for:

- training of personnel involved in resolving crisis situations,

- development and testing of early warning and alert systems,

- public information,

- creation of possible scenarios and exercises, proposal for connection with simulation,

- analyzing reports from exercises.

In prevention, it is assumed that such systems can help provide the necessary map data, storage of stored materials, performing emergency exercises, real-time monitoring, assigning tasks to workers or activating individual warning systems (Ristvej et al., 2015).

In this case, the GIS could be a tool to support the training of crisis managers, the Fire Departments, Salvage and Rescue Services, the Police, the Medical Rescue Service and the psychological assistance staff.

\section{The phase of Preparedness (including (Crisis) Planning)}

During the planning phase, the theoretically designed measures of the prevention phase are brought into real form. They allow a reasonable response to the emergence of a crisis phenomenon. The main task of planning is to determine the forces and means needed to address possible crisis phenomena and compare them with realistic resources. The primary objective of this phase is to achieve a certain sufficient level of preparedness for a crisis.

GIS in phase of preparedness can be used:

- to develop crisis plans,

- as a tool for prevention of crisis phenomena,

- for public education in the field of prevention,

- for emergency evacuation management,

- to practice an exercise in interconnection with the simulation,

- to create evaluation reports of exercises.

The role of the system during preparedness is to create individual task schedules, to analyze current needs for Crisis Management and to communicate with the public sector. As well as in the prevention phase, the system can be used by Crisis managers and components of the Integrated Rescue System (Ristvej et al, 2015).

\section{The phase of Rescue and Relief (Reaction)}

The main activities performed during the reaction phase are measures taken immediately after the beginning of crisis phenomena. This fact significantly affects eventual losses of lives or property damage. An adequate response requires that each respective unit's command trained staff, have sufficient logistical and communicational support. 
During this phase it is possible to use GIS particularly for:

- training of personnel involved in resolving crisis phenomena,

- development and testing of warning services,

- information of the public,

- creation of possible scenarios and exercises,

- proposal of the interconnection between GIS and the simulation program,

- analyzing reports from exercises.

In addition to crisis managers and the Integrated Rescue System, the system can be used by various volunteer organizations such as the Red Cross, asylum houses and similar organizations during their response to crisis phenomena.

\section{The phase of Rehabilitation and Reconstruction (including Recovery)}

This phase is characterized by an effort to return the system to the original, or at least comparable, condition. In some cases, however, this phase is also a chance to build an even better system than was before the crisis. Modern systems do not only help to return to the original state of a system, but they can as well help to greatly improve the affected environment. At this stage, information systems allow restoration through maps and models included in the GIS. In this phase, the GIS is mainly used by crisis managers (Ristvej et al., 2015).

GIS are used during recovery and reconstruction for:

- support of reconstruction of destroyed property and infrastructure,

- industrial renewal,

- application of more durable constructions.

This system is much larger and more comprehensive than digital versions of traditional maps. It enables real-time data updating and spatial data publishing and analysis, thus facilitating the decision-making process, making it possible to perceive it as a decision support system for all the stages of the crisis management cycle, with an emphasis on response and recovery (Ristvej and Zagorecki, 2011). At the same time, it can be perceived as a basic information system for further informational superstructures in the process of risk assessment within particular phases of the Crisis Management Cycle.

\section{Possibilities of the interconnection between simulation technologies and GIS within Crisis} Management

Within crisis management, the simulation technologies are mainly used during the phases of Prevention (including Mitigation) and Preparedness (including Crisis Planning). In the sense of implementation at the University of Žilina we are using it within the newly built Laboratory of Modelling and Simulation of Crisis Phenomena in Transport and in different environments. The main focus is to support decision making in crisis management and prepare crisis managers to solve different situations.

One example is the Unified Information System of Economic Mobilisation in the Slovak Republic with the specific programme EPSIS.

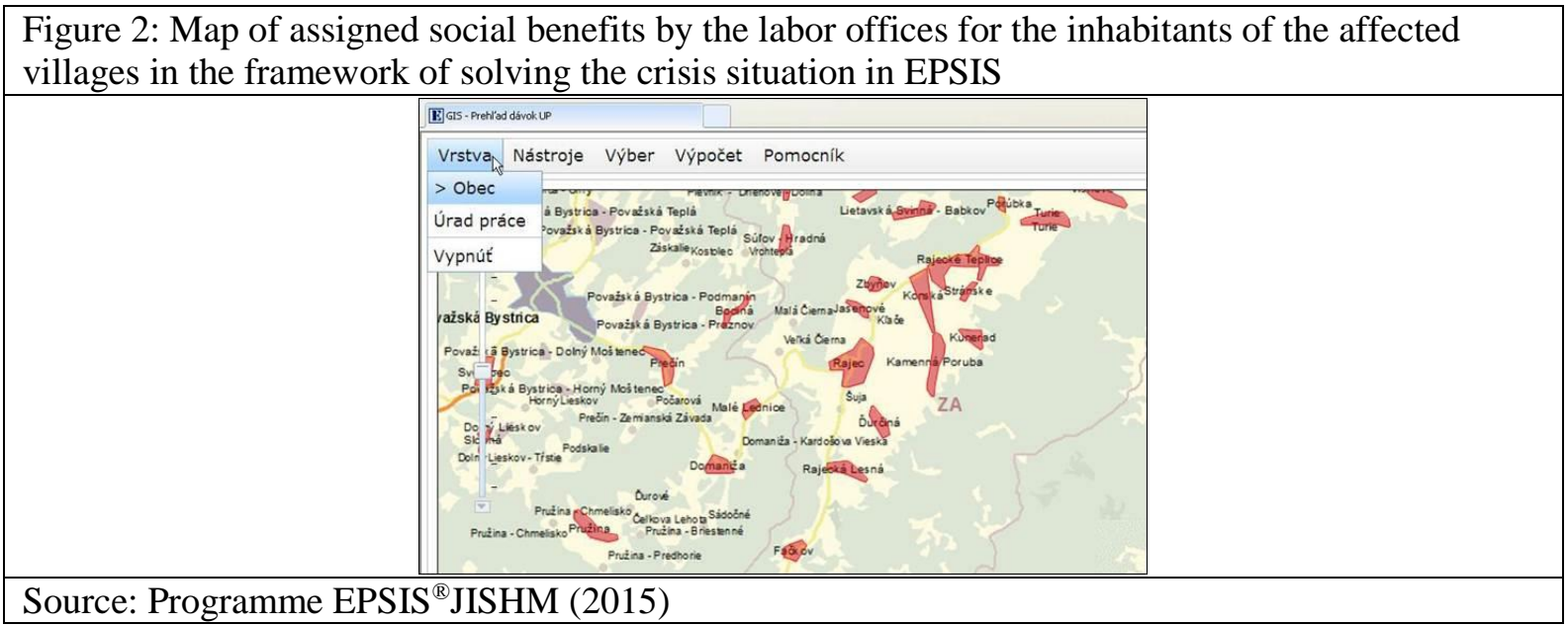


The Laboratory of Modelling and Simulation of Crisis Phenomena in Transport and in different environments enables the simulation of various types of crisis phenomena in different environments. The use of simulation technologies could make planning of emergency measures more effective, identification of forces and resources, needed to cope with the situation more precise and it could also verify whether the planned resources are sufficient or not (Ristvej et al., 2015).

The program VR-Forces is a comprehensive simulation tool that allows us to simulate different situations in a real or fictional map background. It contains a vast set of features and models in attempt to provide as realistic an output as possible. It uses the OpenFlight format of the digitized terrain, which enables 3D modelling in real time. The simulated environment can therefore be displayed in 2D and 3D formats as well as in real-time and non-real-time. Outputs from the program are displayed in the map background, chosen from the included library. It is also possible to export our outputs into external map backgrounds, such as those of GIS and Google maps (Petz, 2009).

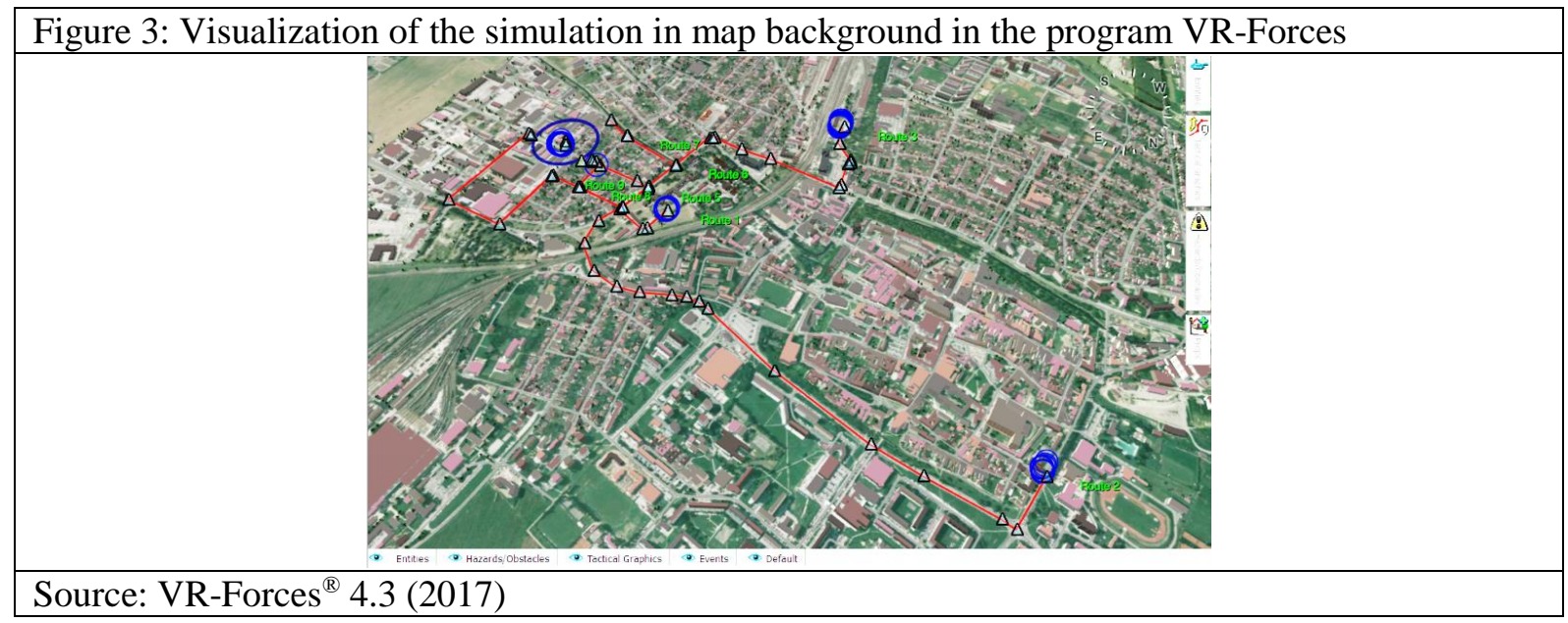

For a constructive simulation, we can use different modules. Every module represents certain type of crisis situation. To improve the effectiveness of decision making, the Laboratory of Modelling and Simulation of Crisis Phenomena in Transport and in different environments at the University Science Park of the University of Žilina has four modules for creating crisis scenarios at its disposal at the moment:

- mass traffic accident,

- dissemination and detection of chemical agents,

- chemical fields (consequences of the use of chemical weapons, contamination and decontamination),

- the leakage of radioactive substances.

Within these modules, it is possible to simulate actions like medical treatment, contamination and decontamination of the territory, vehicles and people. It is also possible to measure contamination and radioactive radiation, to build a dry line, a wet line or decontamination tent etc.

Real map backgrounds, on which we can display created scenarios, represent two regions in Slovak republic, namely Jaslovské Bohunice and the surroundings of Banská Bystrica and Zvolen. In the near future, this laboratory is expected to obtain further map backgrounds, such as surroundings of the city of Žilina and the region of Žilina.

The program VR-Forces has a wide range of usage. It can be a tool for creating new methods and procedures for risk analysis and its optimization for different areas of human activity, whether in the technical, technological, social or the natural environment.

By the use of simulations, it is possible to create complex risk assessments in diverse environments and to propose preventive measures of both a managerial and technical nature. They can also assist in verifying and assessing the competences and tasks of individual elements of the state security system as well as in optimizing its structure.

One of the basic possibilities of this program is to address the crisis phenomena of a natural, social and economic nature. The usage is mainly oriented towards the transport system, where it is possible 
to create simulations of mass traffic accidents or accidents that involve the leakage of hazardous chemical agents, including radioactive substances.

Another area of application is within a joint rescue service, where the simulation allows personnel to verify the effectiveness of deployed forces and resources during an emergency response. It can also be used to assess the functionality of critical infrastructure, to verify emergency plans, to create intelligent systems in crisis management etc.

Last but not least, they can serve as an effective tool for the preparation of current and future experts in the field of crisis management. Using simulations, they could improve their decision-making capabilities under conditions of uncertainty.

\section{Conclusion}

With the advances in information technology and in particular in widespread acceptance of such, it is important to place increasing emphasis on the increasing role of information systems in crisis management with support of GIS. This importance applies to at all phases of the cycle of crisis management. Information systems supporting decision-making in crisis management reflect the complexity and diversity of challenges faced by crisis management at different phases of its cycle as well as the complexity of the entire process of determining solutions for crisis situations. Regarding the risks, good references can be found at Holla (2015) and Rehak et al. (2016).

It can be concluded that at present the Slovak Republic has sufficient information and IT support and a base for processes of crises situation solutions however, it can be developed more. The main reason for the lack of implementation into crisis management is not the unavailability of solutions but, in particular, the lack of awareness of parties concerned and authorized with management, about the existence of appropriate solutions and in particular about their potential benefits. On the other levels of crisis management, it is the lack of preparedness, whether of operators or their superiors, as well as the unwillingness or rather ignorance of technologies based on the Open Source solutions - these are the conclusions of the project 7FP COBACORE. However, the existence of a comprehensive national information system which would contain an application or separate information system for crisis management with implementation of GIS is absent. This also opens the path for investigation and other options in this area. The importance of GIS implementation is getting more and more important and not only in crisis management.

\section{Acknowledgment}

This article was created as one of the project outcomes of work co-funded by the Slovak Research and Development Agency under the contract No. SK-CN-2017-0023 Enhancing Cooperation of the Ningbo University of Technology and the University of Žilina in research, innovation and cooperation within the topic of "Intelligent Transport Systems".

\section{References}

EPSIS ${ }^{\circledR}$ JISHM. (2015). Use of the software. Accessed on: 2015-10-10.

Holla, K. (2007). Dealing with Key Terms in Risk Analysis and Phenomenon of Uncer-tainty in this Process, In:

Komunikácie - Communications - Scientific Letters of the University of Žilina, vol. 9, No. 4, pp. 59-61, ISSN 1335-4205.

Menon, N.V.C. \& Sahay, R. (2006). Role of Geoinformatics for Disaster Risk Manage-ment, (on-line). Accessed on: 201210-10, Available at: http://www.gisdevelopment.net/magazine/years/2006/oct/26_1.htm .

Petz, I. \& Necas, P. (2009). Simulation Techniques and Modelling in Training, In: ICMT '09: International conference on Military Technologies 2009: 5 to 6 May 2009, Brno. -Brno: University of Defence, 2009. -ISBN 978-80-72316489. pp. 482485.

Rehak D, Hromada M, Novotny P. (2016) European Critical Infrastructure Risk and Safety Management. Chemical Engineering Transactions, 2016, Vol. 48, pp. 943-948. ISBN 978-88-95608-39-6. ISSN 2283-9216. DOI:

10.3303/CET1648158.

Ristvej, J. - Zagorecki, A. (2011) : Information Systems for Crisis Management - Current applications and future directions, In: Komunikácie - Communications - Scientific Letters of the University of Žilina, Vol. 13, Iss. 2, 2011, p. 59-63, ISSN: 1335-4205.

Ristvej, J., Zagorecki, A. \& Riska, T. (2015). Crisis Management II. - part 2., Appli-cation Software fot Crisis Management. 1. edition. Zilina: University of Zilina,/ EDIS - publishing center ŽU. pp. 272. ISBN 978-80-5541073-9.

Šimák L. (2016). Crisis Management in Public Administration. 2. edition. Žilina: Uni-versity of Žilina, EDIS - UNIZA press, ISBN 978-80-554-1165-1.

VR-Forces ${ }^{\circledR}$ 4.3. (2017). Use of the software. Accessed on: 2017-10-10.

Walle, van de, B. a col. (2010). Information Systems for Emergency Management. New York: ME. Sharpe, 2010, ISBN 978$0-7656-2134-4$ 